\title{
Caseinoglycomacropeptide Inhibits Adhesion of Pathogenic Escherichia coli Strains to Human Cells in Culture
}

\author{
J. R. Rhoades, ${ }^{1}$ G. R. Gibson, ${ }^{2}$ K. Formentin, ${ }^{3}$ M. Beer, ${ }^{3}$ \\ N. Greenberg, ${ }^{3}$ and R. A. Rastall ${ }^{1}$ \\ ${ }^{1}$ Food and Bioprocessing Sciences Unit and \\ ${ }^{2}$ Food Microbial Sciences Unit, School of Food Biosciences, \\ The University of Reading, Reading, UK \\ ${ }^{3}$ Novartis Medical Nutrition, Nyon, Switzerland
}

\section{ABSTRACT}

Caseinoglycomacropeptide (CGMP) derived from $\kappa$ casein was investigated for its ability to inhibit the adhesion of 3 strains of verotoxigenic Escherichia coli (VTEC) and 3 strains of enteropathogenic Escherichia coli (EPEC) to human HT29 tissue cell cultures. Effects on adhesion of Desulfovibrio desulfuricans, Lactobacillus pentosus, Lactobacillus casei, Lactobacillus acidophilus, and Lactobacillus gasseri were also investigated. Generally, CGMP exerted effective anti-adhesive properties at a dose of $2.5 \mathrm{mg} / \mathrm{mL}$, albeit with a high degree of strain specificity. The CGMP reduced adhesion of VTEC strains to $<50 \%$ of the control and reduced adhesion of EPEC strains to between 80 and $10 \%$ of the control. The CGMP also reduced the adhesion of $L$. pentosus and $L$. casei to 44 and $42 \%$, respectively. A slight but significant reduction of $L$. acidophilus, to $81 \%$, was observed, but no significant effects were detected with either Dsv. desulfuricans or L. gasseri. Further investigation of the dose response relationships with the $E$. coli strains gave IC50 values ranging between 0.12 and $1.06 \mathrm{mg} / \mathrm{mL}$.

(Key words: caseinoglycomacropeptide, bacterial adhesion, Escherichia coli, probiotic)

Abbreviation key: CGMP = caseinoglycomacropeptide, EPEC = enteropathogenic Escherichia coli, SDMEM = Dulbecco's modified Eagle's medium supplemented with 5\% (vol/vol) fetal bovine serum and $1 \%(\mathrm{vol} / \mathrm{vol})$ nonessential amino acid solution, VTEC = verotoxigenic Escherichia coli.

\section{INTRODUCTION}

It is now established that adhesion to host cell surfaces is an essential step for the pathogenesis of certain

Received February 14, 2005.

Accepted June 7, 2005.

Corresponding author: R. A. Rastall; e-mail: r.a.rastall@rdg.ac.uk. bacteria, including those that have effects within the human gut. This interaction frequently involves the recognition of one or more host cell receptors by bacterial adhesion (Sharon and Ofek, 2000). These host cell receptors are often cell-surface oligosaccharides (Ofek et al., 2003). Such oligosaccharides can also be conjugated to dairy proteins, a convenient and commercialized form of which is caseinoglycomacropeptide (CGMP; Brody, 2000). As such, if these molecules are present in situ, they may act as decoys for relevant pathogens. There is clearly much potential for a prophylactic approach to infection control by means of incorporating anti-adhesive molecules into the diet with the goal of reducing the adhesion of common gastrointestinal pathogens. However, in vitro laboratory tests are needed to determine the most effective molecules to develop as ingredients and their target strains.

Caseinoglycomacropeptide has been found to inhibit adhesion of Streptococcus sobrinus, Streptococcus sanguis, Streptococcus mutans, and Actinomyces viscosus to erythrocytes and polystyrene surfaces (Neeser et al., 1988). It has also been shown to inhibit binding of cholera toxin to Chinese Hamster ovary cells at concentrations as low as 20 ppm (Kawasaki et al., 1992). Similar activity was observed with binding of $E$. coli heat-labile enterotoxins LT-I and LT-II to Chinese Hamster ovary cells (Isoda et al., 1990). The feeding of $1 \mathrm{mg}$ of CGMP/d protected $100 \%$ of mice against LT-I and protected $80 \%$ against LT-II. More recently, CGMP was shown to reduce Escherichia coli-induced diarrhea in infant rhesus monkeys (Brück et al., 2003). The postulated mechanism of effect was an anti-adhesive capacity of the CGMP to $E$. coli.

In this study, we examined the potential of CGMP to inhibit adhesion of pathogenic strains of $E$. coli and compared this with similar effects in other selected gut bacteria, including some probiotic lactobacilli.

\section{MATERIALS AND METHODS}

\section{Microbiological Media and Chemicals}

Microbiological media were from Oxoid Ltd., Basingstoke, UK. These were plate count agar, de Man Ro- 
gosa Sharpe agar and broth, and maximum recovery diluent. All were prepared according to the manufacturer's instructions.

Dulbecco's, Modified Eagle's Medium with Glutamax-1 and fetal bovine serum were purchased from GIBCO, Invitrogen Ltd. (Paisley, UK).

The following chemicals were obtained from SigmaAldrich Chemical Co. Ltd. (Poole, UK): PBS tablets (pH $7.2 \pm 0.2 ; 0.1 \mathrm{M})$, nonessential amino acid solution, and Trypsin-EDTA solution [500 N $\alpha$-benzoyl-L-arginine ethyl ester (BAEE) units of porcine trypsin and $180 \mu \mathrm{g}$ of EDTA/mL].

\section{Bacterial Cultures}

Nontoxigenic (verotoxigenic) $E$. coli O157:H7 (VTEC) isolates were obtained from the National Collection of Type Cultures (Colindale, London, UK). Enteropathogenic $E$. coli (EPEC) isolates were resuscitated from freeze-dried ampules stored at ambient temperature since 1976. These were originally obtained from the Salmonella and Shigella Reference Laboratory [Public Health Laboratory Service (now Health Protection Agency), Colindale, London, UK] and were isolated from infant diarrhea cases. Desulfovibrio desulfuricans strain NCIMB 12833 was obtained from the National Collection of Industrial and Marine Bacteria, United Kingdom. Bacterial isolates were stored at $-80^{\circ} \mathrm{C}$ on cryogenic culture storage beads. Working cultures on slopes of plate count agar in universal bottles were prepared from the beads and stored for up to $1 \mathrm{mo}$ at $4^{\circ} \mathrm{C}$. A plate count agar plate was streaked each time the slope cultures were used to confirm culture purity.

Escherichia coli broth cultures for adhesion assays were grown in Dulbecco's modified Eagle's medium supplemented with $5 \%$ (vol/vol) fetal bovine serum and $1 \%$ (vol/vol) nonessential amino acid solution (SDMEM). For each strain, broth was inoculated from a slope culture and incubated anaerobically at $37^{\circ} \mathrm{C}$ for 18 to $24 \mathrm{~h}$. The overnight culture was then inoculated (1\%, vol/vol) into fresh SDMEM and incubated for a further 18 to $24 \mathrm{~h}$ under the same conditions. This procedure was repeated once more. On the day of the assay, a $10 \%$ (vol/vol) inoculum was placed into prewarmed SDMEM and incubated for $4 \mathrm{~h}$ anaerobically at $37^{\circ} \mathrm{C}$.

Lactobacilli were grown in de Man, Rogosa, and Sharpe agar and broth and treated for adhesion assay as described previously.

Desulfovibrio desulfuricans was cultured in Postgate's $\mathrm{E}$ medium prepared by combining the following ingredients in a conical flask: $0.5 \mathrm{~g}$ of $\mathrm{KH}_{2} \mathrm{PO}_{4}, 1.0 \mathrm{~g}$ of $\mathrm{NH}_{4} \mathrm{Cl}, 1.0 \mathrm{~g}$ of $\mathrm{Na}_{2} \mathrm{SO}_{4}, 0.51 \mathrm{~g}$ of $\mathrm{CaCl}_{2}, 2.0 \mathrm{~g}$ of
$\mathrm{MgCl}_{2} \cdot 7 \mathrm{H}_{2} \mathrm{O}, 3.5 \mathrm{~g}$ of sodium lactate, $1.0 \mathrm{~g}$ of yeast extract, $0.1 \mathrm{~g}$ of ascorbic acid, $0.1 \mathrm{~g}$ of sodium thioglycollate, $0.5 \mathrm{~g}$ of $\mathrm{FeSO}_{4} \cdot 7 \mathrm{H}_{2} \mathrm{O}$, and $1 \mathrm{~L}$ of tap water. The medium was boiled to dissolve the ingredients and cooled to approximately $50^{\circ} \mathrm{C}$. Culture $\mathrm{pH}$ was adjusted to 7.6 with $1.0 \mathrm{M} \mathrm{NaOH}$. The medium was reboiled and transferred immediately to an anaerobic cabinet $\left(80 \% \mathrm{~N}_{2}, 10 \% \mathrm{CO}_{2}, 10 \% \mathrm{H}_{2} ; 37^{\circ} \mathrm{C}\right)$, allowed to cool until hand-hot, and dispensed into Hungate tubes (10 $\mathrm{mL}$ per tube). The Hungate tubes were autoclaved at $121^{\circ} \mathrm{C}$ for 15 min. Postgate's medium E agar was prepared as described previously but with the addition of $15 \mathrm{~g}$ of agar no. 1. Following $\mathrm{pH}$ adjustment, the agar medium was dispensed into screw-capped bottles and autoclaved at $121^{\circ} \mathrm{C}$ for $15 \mathrm{~min}$. The agar was cooled to $50^{\circ} \mathrm{C}$ and dispensed into Petri dishes. Once set, the agar plates were transferred into the anaerobic cabinet $4 \mathrm{~d}$ prior to use. Desulfovibrio desulfuricans was grown on Postgate's E medium in Hungate tubes anaerobically at $37^{\circ} \mathrm{C}$ for up to $5 \mathrm{~d}$. Working cultures in Hungate tubes were stored for up to 2 mo at ambient temperature. To prepare cultures for the adhesion assay, $1.0 \mathrm{~mL}$ of stock culture was inoculated into a Hungate tube and incubated for $24 \mathrm{~h}$. A 1-mL aliquot was taken from this tube, inoculated into a fresh Hungate tube, and incubated for a further $24 \mathrm{~h}$.

\section{Cell Cultures}

The HT29 human colon adenocarcinoma epithelial cells were obtained from the European Collection of Cell Cultures, Center for Applied Microbiology and Research (Porton Down, UK). Cells were grown in 25 $\mathrm{cm}^{2}$ of tissue culture flasks in SDMEM at $37^{\circ} \mathrm{C}$ in $5 \%$ $\mathrm{CO}_{2}$ until approximately $90 \%$ confluent, split according to the recommended method of the European Collection of Cell Cultures, and stored in aliquots over liquid nitrogen. These aliquots were used to seed 25$\mathrm{cm}^{2}$ flasks, which, following growth, were split into 12 -well tissue culture plates. The 12 -well plates were grown to approximately $90 \%$ confluence before being used for the adhesion assays.

\section{Assay Method}

Adhesion assays were carried out as follows. A culture of the test strain was prepared as described previously and then diluted to 1:500 in PBS. The viable count of the diluted suspension was determined by spread plating onto plate count agar; decimal dilutions were carried out in maximum recovery diluent as appropriate. The CGMP was dissolved in PBS $(2.5 \mathrm{mg} /$ $\mathrm{mL}$ ) and sterilized by passing through a $0.2-\mu \mathrm{m}$ syringe filter. The CGMP was further diluted in sterile 
Table 1. Adhesion of bacteria to HT-29 cells.

\begin{tabular}{|c|c|c|c|c|}
\hline \multirow[b]{2}{*}{ Test organism } & \multicolumn{2}{|c|}{ Mean adhesion } & \multirow[b]{2}{*}{$P^{2}$} & \multirow{2}{*}{$\begin{array}{l}\text { Adhesion } \\
\text { relative to PBS } \\
\text { control }(\%)\end{array}$} \\
\hline & PBS & $\mathrm{CGMP}^{1}$ & & \\
\hline & $-\left(\log _{10} \mathrm{c}\right.$ & $1 \pm \mathrm{SD})-$ & & \\
\hline Escherichia coli NCTC 12900 & $4.76 \pm 0.154$ & $4.41 \pm 0.281$ & 0.136 & 51 \\
\hline E. coli NCTC 13127 & $4.44 \pm 0.071$ & $4.10 \pm 0.089$ & 0.006 & 46 \\
\hline E. coli NCTC 13128 & $4.68 \pm 0.084$ & $4.17 \pm 0.049$ & 0.001 & 31 \\
\hline E. coli O111:H27 & $5.56 \pm 0.012$ & $5.50 \pm 0.021$ & 0.016 & 87 \\
\hline E. coli O119:H4 & $5.24 \pm 0.014$ & $4.80 \pm 0.050$ & 0.000 & 37 \\
\hline E. coli O128:H12 & $5.50 \pm 0.028$ & $4.06 \pm 0.105$ & 0.000 & 4 \\
\hline Desulfovibrio desulfuricans & $5.52 \pm 0.066$ & $5.38 \pm 0.112$ & 0.140 & 72 \\
\hline Lactobacillus pentosus & $3.92 \pm 0.071$ & $3.57 \pm 0.036$ & 0.002 & 44 \\
\hline L. acidophilus & $4.99 \pm 0.050$ & $4.89 \pm 0.029$ & 0.041 & 81 \\
\hline L. casei & $3.85 \pm 0.118$ & $3.48 \pm 0.087$ & 0.012 & 42 \\
\hline L. gasseri & $5.06 \pm 0.063$ & $5.07 \pm 0.218$ & 0.901 & 100 \\
\hline
\end{tabular}

PBS as required. The SDMEM was aspirated from a 12 -well tissue culture plate with near-confluent monolayers of HT29 cells (described previously). The monolayers were then washed by pipetting in $1 \mathrm{~mL}$ of sterile PBS per well, swirling by hand, and then aspirating. A $0.5-\mathrm{mL}$ aliquot of CGMP solution was added to a well followed by $0.5 \mathrm{~mL}$ of the bacterial suspension in PBS. A control using sterile PBS in place of CGMP solution was prepared. All assays were performed in triplicate. The plates were swirled by hand to mix and then incubated at $37^{\circ} \mathrm{C}$ aerobically for $2 \mathrm{~h}$.

After incubation, the bacterial suspension was aspirated from the wells. A 1-mL aliquot of PBS was added to each well. The plate was swirled briefly by hand, and the PBS was removed. This washing step was repeated twice more. A 70- $\mu \mathrm{L}$ aliquot of trypsin-EDTA solution was added to each well, the plate was rocked to ensure even coverage, and then was incubated at $37^{\circ} \mathrm{C}$ for $5 \mathrm{~min}$. A $1-\mathrm{mL}$ aliquot of PBS was then pipetted into each well, and the pipette was mixed until the monolayer was completely dislodged and clumps were broken up (as determined visually). Bacteria remaining in the well were then enumerated by plate counting on appropriate agar plates with decimal dilu-

Table 2. IC50 values of caseinoglycomacropeptide (CGMP) toward Escherichia coli strains. ${ }^{1}$

\begin{tabular}{ll}
\hline E. coli strain & $\begin{array}{l}\text { IC50 } \\
(\mathrm{mg} / \mathrm{mL})\end{array}$ \\
\hline O157:H7 NCTC 12900 & 0.14 \\
O157:H7 NCTC 13127 & 0.16 \\
O157:H7 NCTC 13128 & 0.12 \\
O119:H4 & 0.35 \\
O128:H12 & 1.06 \\
\hline
\end{tabular}

${ }^{1}$ Each dose was tested in triplicate. tions performed in maximum recovery diluent as required. All plates were incubated at $37^{\circ} \mathrm{C}$ for 18 to 24 $\mathrm{h}$ before colonies were enumerated. Viable counts were calculated for all wells and for the inoculum and were expressed as $\mathrm{cfu} / \mathrm{mL}$. For each test, the mean and standard error of the triplicate wells were calculated. Statistical significances were determined by one-way ANOVA using Minitab version 14.

\section{RESULTS AND DISCUSSION}

The CGMP was screened for activity against the chosen bacteria at a concentration of $2.5 \mathrm{mg} / \mathrm{mL}$. These results are presented in Table 1 . The VTEC strains were inhibited to 31 to $51 \%$ adhesion relative to the control value. In contrast, serotype variation was evident in the sensitivities of the 3 EPEC serotypes to CGMP with adhesion varying from 4 to $87 \%$ of the control value (Table 1 ).

The CGMP also resulted in a decrease in adhesion of 3 of the 4 lactobacilli tested. Lactobacillus casei and L. pentosus were both reduced to around $40 \%$ of the control level of adhesion, and L. acidophilus was reduced by a much lower degree, to $81 \%$ of the control value. Lactobacillus gasseri, however, was completely resistant to the anti-adhesive activity of CGMP. The effect of CGMP on the adhesion of probiotic bacteria has not been tested to date and this may have implications for the application of CGMP as a dietary antiadhesive. For CGMP to exert desirable effects on the gut microflora, the anti-adhesive effect would need to be selective for pathogens and potentially harmful organisms over the desirable probiotic flora.

Desulfovibrio desulfuricans was also investigated in this study, as this organism is known to produce toxic $\mathrm{H}_{2} \mathrm{~S}$ by reduction of dietary sulfate in the colon and is 


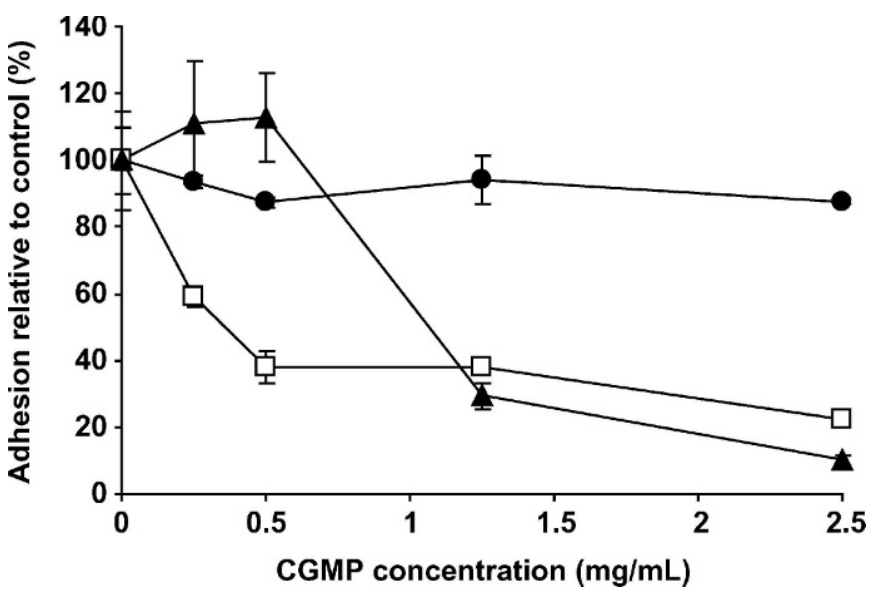

Figure 1. Anti-adhesive activity of caseinoglycomacropeptide (CGMP) against Escherichia coli serotypes O111:H27 (•), O119:H4 $(\square)$, and O128:H12 (A). Error bars indicate standard errors of the means of triplicate assays.

postulated to be involved in the etiology of ulcerative colitis (Pitcher and Cummings, 1996; Willis et al., 1997). However, CGMP did not have any significant effect on adhesion of Dsv. desulfuricans.

The ability of CGMP to inhibit the $E$. coli strains was further investigated by determining the dose-response relationships and IC50 values, which are presented in Table 2. Figures 1 and 2 show the dose-response curves for EPEC (with the exception of strain O111:H27, which was not significantly inhibited; Table 1), and VTEC strains, respectively. Inhibition was apparent at low concentrations of CGMP, and IC50 values

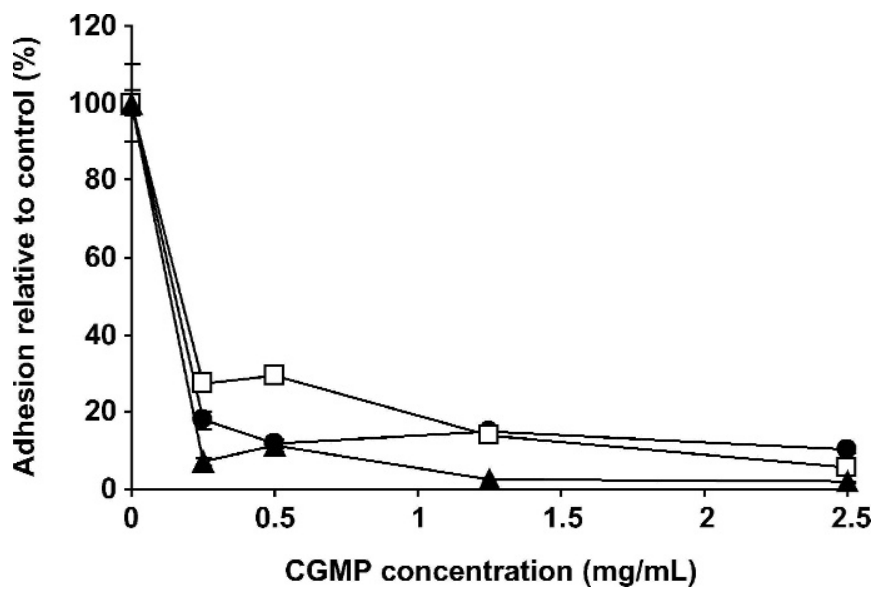

Figure 2. Anti-adhesive activity of caseinoglycomacropeptide (CGMP) against Escherichia coli O157:H7 strains NCTC $12900(\bullet)$, NCTC $13127(\square)$, and NCTC $13128(\boldsymbol{\Delta})$. Error bars indicate standard errors of the means of triplicate assays. ranged from 0.12 to $1.06 \mathrm{mg} / \mathrm{mL}$. The CGMP displayed good anti-adhesive activity against VTEC strains but had marked strain specificity with the EPEC strains; O111:H27 was virtually unaffected, but, with O128:H12, adhesion was reduced to $<5 \%$ of the control value.

It is clear that CGMP has some potential as a prophylactic anti-adhesive. However, it is also clear that CGMP showed strain-dependent behavior. The reasons for such strain variability are not yet apparent. Caseinoglycomacropeptide carries 3 glycosylation sites with a heterogeneous array of glycans based on a core of $\mathrm{Gal} \beta 1 \rightarrow 3 \mathrm{GalNAc}$ (Sato and Itoh, 1992). The undecorated core accounts for $6.3 \%$ of the glycans and this core can carry $N$-acetylneuraminic acid residues $\alpha-1$ to 3 -linked to the galactose ( $18.4 \%$ of glycans), $\alpha$ 1 to 6 -linked to the $N$-acetylgalactosamine $(18.5 \%$ of glycans), or at both positions (56\% of glycans; Sato and Itoh, 1992). Glycans carrying terminal $N$-acetylneuraminic acid residues (commonly referred to as sialic acids) are known to act as receptors for several pathogens, including enterotoxigenic and enteroaggregative E. coli strains (Korhonen et al., 1984; Ofek et al., 2003). Sialic acids have also been implicated in the binding of Lactobacillus casei (Ofek et al., 2003). Other lactobacilli have been reported to adhere to mucins (Ofek et al., 2003), but the detailed receptor specificity is unknown. The majority of studies on the inhibition of adhesion of bacteria to human cells by CGMP have utilized single strains of pathogens, and we have an incomplete knowledge of the cellular receptors for different strains of pathogenic bacteria and for probiotic organisms.

Also, the system used here is a model system based on a human colon cancer cell line, and it is conceivable that different results would be obtained with different cell types. Nevertheless, we have demonstrated the biological potential for CGMP to inhibit the binding of pathogenic strains of $E$. coli, albeit with some concomitant effects on probiotic bacteria.

\section{REFERENCES}

Brody, E. P. 2000. Biological activities of bovine glycomacropeptide. Br. J. Nutr. 84:S39-S46.

Brück, W. B., S. Kelleher, G. R. Gibson, K. E. Nielsen, D. E. W. Chatterton, and B. Lönnerdal. 2003. rRNA probes used to quantify the effects of glycomacropeptide and $\alpha$-lactalbumin supplementation on the predominant groups of intestinal microflora of infant rhesus monkeys challenged with enteropathogenic Escherichia coli. J. Ped. Gastroenterol. Nutr. 37:273-280.

Isoda, H., Y. Kawasaki, M. Tanimoto, S. Dosako, and T. Idota. 1990. Use of compounds containing or binding sialic acid to neutralise bacterial toxins. European Patent 385118.

Kawasaki, Y., H. Isoda, M. Tanimoto, S. Dosako, T. Idota, and K. Ahiko. 1992. Inhibition by lactoferrin and $\kappa$-casein glycomacropeptide of binding of cholera toxin to its receptor. Biosci. Biotechnol. Biochem. 56:195-198. 
Korhonen, T. K., V. Väisänen-Rhen, M. Rhen, A. Pere, J. Parkkinen, and J. Finne. 1984. Escherichia coli fimbriae recognising sialyl galactosides. J. Bacteriol. 159:762-766.

Neeser, J. R., A. Chambaz, S. D. Vedovo, M. J. Prigent, and B. Guggenheim. 1988. Specific and non-specific inhibition of adhesion of oral actinomyces and streptococci to erythrocytes and polystyrene by caseinoglycopeptide derivatives. Infect. Immun. 56:3201-3208.

Ofek, I., D. L. Hasty, and R. J. Doyle. 2003. Bacterial Adhesion to Animal Cells and Tissues. ASM Press, Washington, DC.
Pitcher, M. C., and J. H. Cummings. 1996. Hydrogen sulphide: A bacterial toxin in ulcerative colitis? Gut 39:1-4.

Sato, T., and T. Itoh. 1992. Variations and distributions of O-glycosidically linked sugar chains in bovine $O$-casein. J. Dairy Sci. $75: 1768-1774$.

Sharon, N., and I. Ofek. 2000. Safe as mother's milk: Carbohydrates as future anti-adhesion drugs for bacterial diseases. Glycoconj. J. 17:659-664.

Willis, C. L., J. H. Cummings, G. Neale, and G. R. Gibson. 1997. Nutritional aspects of dissimilatory sulfate reduction in the human large intestine. Curr. Microbiol. 35:294-298. 